greater ability of sorghum stomata to recover from severe drought, as compared with those of maize, was confirmed in the field. Thus, some of the wellknown resistance to drought by this crop is probably due to the ability of its stomata to recover from severe water shortage. Studies of the behaviour of stomata during and after recovery from drought is being extended to other crop plants. The effect of soil drying on humus decomposition and mineralization of soil nitrogen has been further studied, and it has been found that addition of activated charcoal to a dry soil completely inhibited the flush of decomposition that normally occurs when a dry soil is moistened. This supports the hypothesis that drying a soil increases the amount of decomposable organic material going into solution, and further experiments have lent support to the idea.

Ecological work during the year was largely concerned with the determination of elimatic types of vegetation in south Kenya. An account is given of twenty-one years work on Cassava breeding for resistance to mosaic and brown streak viruses. Projects on maize breeding include a study of resistance in maize to the virus of streak disease and maintenance of rust races and the pure lines of maize resistant to one or other of the known rust races so that, in the event of new races appearing in the field, genetic studies may be resumed. A Sorghum breeding research scheme has been inaugurated. The nematologist has completed a survey of plant parasitic nematodes of East Africa. Species of root-knot nematodes have been found in indigenous forest throughout East Africa and may constitute a problem. for future development of crops in such areas. The Animal Husbandry Division is making a study of the nutritive properties of maize with the object of finding why maize is an unsatisfactory pig food and whether it would be economic to correct its detrimental properties. Results to date suggest that supplementary nicotinic acid would permit the effective use of high-maize rations.

E. C. Humphries

\title{
EXCAVATIONS AT LA VENTA, MEXICO
}

\begin{abstract}
A
RECENT publication by the Bureau of American Ethnology of the Smithsonian Institution entitled "Excavations at La Venta, Tabasco, 1955", represents an important contribution to Mexican archæology*. It should be studied in conjunction with previous Smithsonian reports which are quoted in the bibliography, particularly "La Venta, Tabasco. A Study of Olmec Ceramics and Art" (Bulletin 153 of the Bureau), also by Dr. P. Drucker.

The La Venta or Olmec Culture remains elusive both in its distribution and in its temporal range, but now we know a great deal more than we did about the type site, and for the first time we have a series of radiocarbon dates which give an idea when that particular site was occupied. The Olmec Culture has given rise to a notable art style, examples of which are found over a far wider area than the rather limited parts of the tropical forests of the Gulf Coast of southern Vera Cruz and Tabasco, where its chief monuments have been found. Broadly speaking, this art style is characterized by stone carvings and pottery figurines representing beings with puffy, loose-lipped 'baby faces', some of which take the form of colossal stone heads, and by highly stylized jaguar faces obviously related to the human ones. These are sufficiently prominent to provide strong evidence of jaguar worship, even without some remarkable features of La Venta which are mentioned below. One of the most important outliers of the style, where it chiefly takes the form of pottery figurines, is at Tlatilco on the outskirts of Mexico City, and this in its turn has relationships of another kind with sites of eomparable age in Guatemala, Eeuador and Peru. In Peru, but not so far in the intervening area, evidence of a strong jaguar cult has been found, and it is tempting to relate it with the Olmec one, although its artistic representations are very different. This is enough to show the importance of the Olmec
\end{abstract}

* Smithsonian Institution: Bureau of American Ethnology. Bulletin No. 170: Excavations at La Venta, Tabasco, 1955. By Philip Drucker, Robert F. Heizer and Robert J. Squier. With Appendixes by Jonas E. Gullberg, G. H. Curtis and A. S. Leopold.
Pp. viii $+312+63$ plates. (Washington, D.C.: Government Printing Office, 1959 .
Culture, and how welcome is further information about it.

La Venta is a ceremonial site with few signs of ordinary dwellings. It occupies a ridge on an island surrounded by swamps, and was accurately planned about an axis running approximately north and south. The portion of it which has been investigated lies north of a large pyramid and consisted of a number of platform mounds disposed about two courts, of which the northern seems to have been the most important. Apart from a limited use of stone facing blocks, and some palisades made of rows of basaltic columns, the actual construction was carried out entirely in clays and sands of various colours, some of which at least must have been carried considerable distances.

In conformity with the usual pattern of Mexican ceremonial sites, at least four major reconstructions have been distinguished in each part of the site which has been investigated, and a most remarkable feature in connexion with each of these stages was the digging of enormous deep pits through the older structures, in which were placed what are interpreted as massive offerings consisting of pavements of slabs of varieties of metamorphic rock, loosely described as serpentine. The largest of these was 28 courses thick, and contained something of the order of 1,000 tons of rock. In at least two cases these underlay an even more remarkable mosaic jaguar mask measuring about 15 by $20 \mathrm{ft}$. of serpentine slabs set in clays and sands of various colours, and it is probable that more remain to be discovered. The facts that these were deliberately buried before a single rainy season had passed, and that none of the rocks of which they were made occurs within less than $60 \mathrm{~km}$. from the site, and some perhaps more than $100 \mathrm{~km}$., add to a most amazing phenomenon. Other features of the site were smaller offerings, not it seems connected with burials, some of which are related in position to the axis of the site; they include many groups of jadeite celts, and a most curious group of typical baby-faced sexless Olmec stone figurines which appear to be arranged to represent some ceremony. 
The nine radiocarbon dates contain some minor inconsistencies, but taken as a whole they justify the conclusion of the authors that the time covered by the four building periods is from about 800 to 400 B.C. This is an important new piece of evidence to add to that which has been accumulating in recent years for the existence of elaborate ceremonial structures in the first millenium B.c., that is to say before the Classic Period in the first millenium A.D. to which belong the famous ceremonial centres of the lowland Maya and those at Teotihuacan and Monte Alban.
Both stages imply the disposal of much labour by a ruling class, witness the carriage of 1,000 tons of stone for more than $60 \mathrm{~km}$. without wheeled transport or pack animals, for a single ritual deposit at La Venta. The chief difference seems to be that clay rather than stone and lime plaster was used for constructional purposes in the pre-Classic sites. The report also gives powerful support to those who believe the Olmec to have preceded the lowland Maya and other high cultures of this part of the American continent.

G. H. S. Bushnelt

\section{MISTLETOE IN AUSTRALIA}

$\mathrm{M}$ ISTLETOE has never been a serious pest in Britain. The Australian species, however, are different and cause extensive losses (C.S.I.R.O., Rural Res., 29 ; 1959). They do not even find a use as Christmas decoration. Only in Tasmania is the parasite not a problem, but why this is so when it occurs widely on the mainland is not known. In the other States, and especially in New South Wales and Queensland, mistletoe damage is so extensive and so costly that it constitutes a problem of national importance.

Areas may be found in which practically every tree has been parasitized. Many of them die, and those that do not produce less timber. One worker has estimated that when 38 per cent of the crown of the host tree has been displaced by mistletoe, wood production is down as much as 55 per cent.

The widespread, outright killing of trees in water catchment areas has led to soil erosion, silting, and higher flood-levels in wet seasons. In agxiculture, mistletoe is a nuisance, as it often kills shade trees.

Forestry departments have found that the incidence of mistletoe attack has been increasing over recent years. For example, records maintained by the Commonwealth Forestry and Timber Bureau on a number of small plots at Kowen show that between 1952 and 1955 the infestation increased from 75 to 79 per cent a year.

Eradication based on amputation of infested branches or felling badly infested trees is much too expensive for large-scale operations. Certain sprays are efficient killers; but it is often difficult to reach all the mistletoe on an affected tree with spray equipment. Biological control methods, using insects or pathogens, hold little hope of success. In 1937, the Forestry Department of Queensland found that possums had a decided liking for mistletoe and apparently preferred it to almost any other type of food. It is possible that before the coming of the white man, these and other leaf-eating animals exerted a strong control on mistletoe. It is impracticable under present conditions to restore the possum population to its former level. Clearing for settlement, resulting in more light and greater numbers of birds around the trees, has probably increased the spread of mistletoe : it seems to grow best where the light is good, and birds are the chief means of spreading the seeds, which stick to their beaks or pass through with their droppings.

Chemicals seemed to offer the only effective means of control, and, in 1948, Mr. G. C. Greenham, of the Commonwealth Scientific and Industrial Research
Organization Division of Plant Industry, began experiments to see whether it would be possible and practical to control the parasite by a selective poison injected into the trunk of the host tree. The work has entailed exhaustive trial and error because of the close physiological association between the host and parasite - a poison that would kill the mistletoe might also be expected to kill or at least seriously damage the tree.

The first poison tried was the selective phytocide, copper sulphate. This gave fair results, but was not good enough, because usually it did not kill more than half the mistletoe. The next step in the investigation was to obtain information about the way in which substances are moved or translocated throughout a tree. This was done by using radioactive isotopes. Supplies of radioactive iron, cobalt and zinc salts were used in the first botanical experiment with radioactive isotopes in Australia.

The third step was to try out the hormone selective weed-killers. So far, about a dozen of these have been checked; the triethanolamine salt of $2,4-D$ was found to be outstanding in that it killed or seriously injured a high proportion of the mistletoe without harming the host eucalyptus.

Other hormone-type compounds and mixtures of them are being tested, and some, including various forms of $2,4-D$, hold considerable promise. The hydrazine salt of $2,4-D$ is being exhaustively tested at present because preliminary trials have shown it to be at least as good as the triethanolamine salt and to have a faster effect.

Mistletoe dies up to two years after the tree has been injected, and the final assessment of the effectiveness of the treatment should be postponed until at least two years have elapsed. Mistletoe surviving after this time may be subjected to the treatment again without harming the host tree, which does not become sensitized to 2,4-D as a result of earlier dosing. Nor does the mistletoe become resistant, and the second treatment will kill about 50 per cent of the remaining parasites. Because of the high rate of re-infestation in some areas, it would be unrealistic to aim at complete eradication. Since the first treatment may be expected to kill 70-90 per cent of the parasites, it is more practical to re-treat the trees every five years.

Information is now available concerning the effect of the treatment on eight species of eucalyptus. Reasonably good results have been obtained for seven of the eight species, and this suggests that the treatment may be suitable for destroying inistletoc on a wide range of eucalyptus hosts. 